Fig. 164, of the medicinal leech, the apical lobe of the nephridium has been wrongly labelled "nephrostome". Will the author please look up M. L. Bhatia's paper (Quart. J. Micr. Sci., 81, 1 ; 1938).

$A$ well-balanced and very useful treatise on littloknown species has resulted from the work of the team. This may be largely due to the training of the majority at the great Marine Biological Station at Woods Hole, Mass. The printing and production are of high class. So, unfortunately, is the price.

N. B. E.

\section{RACE FORMATION IN MAN}

Races

A Study of the Problems of Race Formation in Man. By Dr. Carleton S. Coon, Dr. Stanley M. Garn and Dr. Joseph B. I3irdsell. Pp. xiv +153. (Springfield, Ill. : Charles C. Thomas; Oxford : Blackwell Scientific Publications, Ltd., 1950.) 21s. 6d. net.

$\mathrm{T}$ HIS work defines a race as a somatically unique population or collection of identical populations. The blend of Mongoloid, European White and Polynesian with diffuse Negroid elements in the Hawaiian Islands is considered a race in the meaning of the term proposed, and twenty-nine other populations are distinguished as being probably unique in the same sense.

In discussion of the topic of the character of the skull in man, it is noticed that early man, as represented by archæological finds, was thick in the skull as compared with modern man. Roundheadedness is said to be late Ploistocene in development, common to-day, linked to nothing else in particular and of no discernible functional advantage, but the most extensively measured of all physical criteria. Nevertheless, in connexion with some other physical characteristics, a suggestion is made that genetic variations serve, in the long run, to suit races to different environments. For example, around the Arctic Circle we find uniformly short people, and the authors suggest that selection has favoured those who can store and utilize fat, and escape freezing at their extremities in that climate. The fatty eyeshield of the Mongoloid eye is stated to be a guard against the danger of freezing of the eyes in polar climates. In matters of pigmentation of the eye, the discussion is possibly not equally convincing. Eyes in which there is little pigment in the front of the iris are numerically predominant only in northern Europe, at least in their origins. The authors correlate this distribution with the relatively weak intensity of light in temperate climates. They state that darkeyed people do not 'see better' than light-eyed, but that they resolve images better under conditions of intense illumination. The authority under which this statement is made is not apparent from the text, and personally $I$ cannot estimate its value. The authors say that they do not know any conditions under which a blue eye is better than a brown one.

In controversy, at one point the authors state that one might suppose students of human behaviour would have been interested in relating varieties of behaviour to anatomical, physiological and genetical variations in man. But, as a matter of fact, very few of the findings of the social scientists lend themselves to scientific treatment with the precision which may be accorded the physical aspects of race. The disinterest mentioned might, I suggest, be ascribed to the intervention of psychology, since psychologists are interested in such matters as abilities to resolve images under conditions of bright light. If brown eyes make better marksmen in tropical areas, the army might also be interested.

However, if writers on the subject of the physical aspects of race fall into such deficiencies in precision as they sometimes attribute with some justice to social scientists, then one may recall the fact that Darwin was prompted to formulate his concepts of biological adaptation as a result of reading an essay by Malthus on the "Principle of Population", which contained an element of imprecision. Social scientists are interested in problems in subjects such as politics, religion, art or history, in which the isolation of individual abilities for study is still of interest, but in which the field itself is collective. I agree that a problem of relationship between varieties of behaviour and genetical variation may be said to be outstanding. However, capacities for learned behaviour in man may be widespread and independent of racial constitution as a general rule. R. F. Fortune

\section{ATOMIC PHYSICS FOR THE NON-SPECIALIST}

\section{Atomic Physics}

By Dr. Wolfgang Finkelnburg. Translated from the revised German edition in co-operation with the Author by George E. Brown. (International Series in Pure and Applied Physics.) Pp. $x+498$. (London : MoGraw-Hill Publishing Co., Ltd., 1950.) 55s. $6 d$.

THE subject material of this book covers a wider field than one expects from the title. In addition to those subjects usually associated with atomic physies, the author devotes nearly half his book to nuclear, molecular and solid-state physics. It is not, however, suitable as a text-book for these subjects, the author having chosen to discuss briefly a very wide range of material, with a consequent loss of depth in the treatment of any particular subject. It is intended more as general reading for senior and graduate students of physics, engineering and chemistry, to give them an appreciation of recent developments in fields other than those in which they have acquired some specialist knowledge. Considered from this point of view, it is a good book.

The book has been written with the minimum of experimental detail and theory required to provide some factual basis for discussion, the ease of reading achieved in this way being somewhat offset by rapid changes of subject and the frequent introduction of new ideas. Many recent advances in the various fields are mentioned, including some hypotheses in the current literature which are still in dispute. It is somewhat surprising at first to find subjects such as Heisenberg's theory of multiple meson production presented in much the same way as the experiments of Rutherford on alpha-particle scattering. A successful attempt has been made to emphasize the recent advances in each subject and to indicate the present frontier of knowledge. There is also an emphasis on the inter-relationship of the concepts and basic knowledge required for an understanding of this large field of scientific knowledge.

The text is well illustrated with figures, diagrams and photographic reproductions. On the whole they have been well chosen; for example, the description of instruments of nuclear physics includes photo- 